\title{
Evidence-based Clinical Practice Guidelines for the Periodic Eye Examination in Children Aged 0 to 5 Years in Canada
}

\author{
Joint Clinical Practice Guideline Expert Committee of the Canadian Association \\ of Optometrists and the Canadian Ophthalmological Society: \\ ${ }^{1}$ Representing the Canadian Ophthalmological Society \\ ${ }^{2}$ Representing the Canadian Association of Optometrists \\ ${ }^{3}$ Representing the Canadian Association of Paediatric Ophthalmology and Strabismus
}

Walter T. Delpero, MD FRCSC - Co-Chair ${ }^{1}$

Assistant Professor

University of Ottawa

Department of Ophthalmology

Barbara E. Robinson,

OD MPH PhD FAAO -

Co-Chair ${ }^{2}$

Professor Emeritus

School of Optometry

and Vision Science

University of Waterloo

Jane A. Gardiner, MD FRCSC ${ }^{1,3}$

Clinical Professor

Department of Ophthalmology

and Vision Science

University of British Columbia

British Columbia Children's

Hospital

Louise Nasmith, MDCM FCFP FRCPSC (Hon)

Professor

Department of Family Practice

The University

of British Columbia

Anne Rowan-Legg, MD FRCPC

Consultant Paediatrician

Children's Hospital of Eastern

Ontario and Renfrew

Victoria Hospital

Assistant Professor

University of Ottawa

Department of Pediatrics

Benoît Tousignant,

OD MSc MPH FAAO ${ }^{2}$

Assistant Professor

School of Optometry

Université de Montréal

\section{Abstract}

Background: As eye disease before age 5 years is common, some form of vision screening should be performed on children prior to attending primary school. However, the lack of consistent national recommendations creates confusion for patients, eye care professionals and governments alike.

Methods: The objective of this document is to provide guidance on the recommended timing, intervals and types of ocular assessments for healthy children aged 0 to 5 years. A literature search yielded 403 articles. A multidisciplinary expert committee (comprising two optometrists, a comprehensive ophthalmologist, a pediatric ophthalmologist, a family physician and a pediatrician) independently determined those articles deemed to be key to the clinical question. Articles that were gradable $[\mathrm{n}=16]$ were then submitted for independent critical appraisal by an external review group, which provided a GRADE profile of the reviewed articles to use for assigning a grade of evidence.

Recommendations: In addition to routine screening by a primary health care professional, a comprehensive eye examination by an individual with the expertise to detect risk factors for amblyopia - such as an ophthalmologist or optometrist - is required in early childhood. The findings support the importance of early detection of amblyopia prior to 36 months and no later than 48 months of age via screening with at least 1 comprehensive eye exam prior to age 5 years.

Conclusions: Vision screening performed by primary healthcare providers during routine well-baby/child visits and scheduled vaccinations is an essential part of the detection of ocular disease. However, this early detection potential is limited and a full oculovisual assessment is also recommended prior to the child entering the school system. If amblyopia, strabismus or other eye pathology is detected or suspected that is beyond the scope of the eye care professional examining the patient, a referral to the appropriate specialist can be made, allowing treatment to be initiated in a timely fashion.

KEY WORDS:

amblyopia, children, clinical practice guideline, comprehensive eye examination, infants, periodic eye examination, primary care, refractive error, strabismus, vision screening 


\section{INTRODUCTION}

Vision screening and comprehensive eye examinations are recommended throughout life as a method of uncovering treatable asymptomatic ocular disease that may otherwise go undetected..$^{1-5}$ As eye disease before age 5 years is common, family medicine, pediatric medicine, optometry and ophthalmology have long advised that some form of vision screening should be performed on children prior to attending primary school (Table 1 ). ${ }^{1,3-9}$ In addition to various recommendations from national organizations, vision screening recommendations also vary across provinces, and within provinces by county or even by school board district. The Canadian Ophthalmological Society (COS) and the Canadian Association of Optometrists (CAO) recognized that the lack of consistent national recommendations from ophthalmologists and optometrists regarding screening and comprehensive eye examination intervals was creating confusion for patients, eye care professionals and governments alike. It was further recognized eye care guidelines should include input from the other key healthcare professionals involved in primary health surveillance for children, namely pediatricians and family physicians. COS and CAO thus invited the College of Family Physicians of Canada (CFPC) and the Canadian Paediatric Society (CPS) to each appoint a representative to an interdisciplinary guideline expert committee to develop recommendations based on evidence and the clinical expertise and practice realities of all representatives.

Ideally, guidelines are flexible tools that are based on the best available scientific evidence and clinical information; they also reflect the consensus of professionals in the field and allow healthcare professionals to use their individual judgment in managing their patients. ${ }^{10}$ Guidelines are not intended to provide a "cookbook" approach to medicine or healthcare or to be a replacement for clinical judgment; ${ }^{11}$ rather, they are intended to inform patterns of practice. These guidelines should be considered in this context. Adherence to these guidelines will not necessarily produce successful outcomes in every case. Furthermore, these guidelines are not intended to define or serve as a legal standard of medical $\mathrm{care}^{12}$ and should therefore not be used as a legal resource, as their general nature cannot provide individualized guidance for all patients in all circumstances. ${ }^{11}$ Standards of medical care are specific to all the facts or circumstances involved in an individual case and can be subject to change as scientific knowledge and technology advance, and practice patterns evolve. Indeed, healthcare professionals must consider the needs, preferences, values, and financial and personal circumstances of individual patients, and work within the realities of their healthcare setting.

The objective of this document is to provide guidance on the recommended timing, intervals and types of ocular assessments for healthy children aged 0 to 5 years (e.g. not premature, without chronic systemic disease [e.g. diabetes], without hearing loss or neurodevelopmental disorders.) The intended audience is any Canadian healthcare professional who refers or sees infants and children for an eye examination (i.e. pediatricians, family physicians, primary care providers, ophthalmologists and optometrists, nurses and nurse practitioners). The recommended intervals of examination will also be of interest to the general public and policy makers. It is acknowledged that there are inequities in human, financial and healthcare resources in different regions of the country and that these factors may affect healthcare professionals' and patients' options and decisions. To this extent, these guidelines could be used for advocacy for basic eye care for the pediatric population in underserved areas.

\section{METHODS}

These guidelines were systematically developed and based on a thorough consideration of the medical literature and clinical experience of the interdisciplinary healthcare professionals on the Expert Committee. Where possible, the content of this document was developed in accordance with the Canadian Medical Association Handbook on Clinical Practice Guidelines ${ }^{11}$ and the criteria specified in the 6 domains of the Appraisal of Guidelines Research and Evaluation II (AGREE II) Instrument. ${ }^{13,14}$ These domains cover the following dimensions of guidelines: scope and purpose, stakeholder involvement, rigor of development, clarity and presentation, applicability and editorial independence. In addition, the guideline development checklist by Schünemann and colleagues was consulted and applied where applicable. ${ }^{15}$

The key clinical question for this guideline was, "What are the optimal times and intervals when children aged 0 to 5 years should undergo ocular assessment in order to promote optimal eye health?" To answer this question, searches of PubMed/Medline (1995 through April 2018) were performed by a medical librarian, using appropriate controlled vocabulary and keywords ("amblyopia, refractive error, vision screening, strabismus" combined with variations of the term "comprehensive eye examination"). These searches were further supported by sampling searches of EMBASE, Web of Science and the Cochrane Library. The searches were limited to children and infants 0 to 5 years old and published in peer-reviewed journals written in English or French. All studies were included in the search for well- 
conducted clinical trials and observational studies; studies of amblyopia, amblyogenic risk factors and refractive error; studies performed in primary care and population-based settings; studies of screening tests typically available in primary care settings (e.g. visual acuity tests, red reflex and cover test) or examination techniques used by optometrists and ophthalmologists (e.g. retinoscopy, etc.); and studies with the following outcomes: improved visual acuity, reduced amblyopia, improved school performance and quality of life. Results were not restricted to systematic reviews, randomized controlled trials/controlled clinical trials, and observational studies. Searches were updated on a regular basis and the bibliographies of included studies were checked for further references to relevant studies and papers. (Search strategies are available in Appendix 1). (Inclusion and exclusion criteria are available in Appendix 2.)

The literature search yielded 403 articles. Committee members were asked to review article abstracts and independently indicate articles deemed to be key to the clinical question. All articles that were selected by a majority of the committee $(\geq 4 / 6$ members) as "key" were then reviewed by the co-chairs. Those articles that were gradable [n=16] were then submitted for independent critical appraisal. Other articles that provided context and data regarding the clinical question are cited in the text of this document, but were not used to support recommendations.

Full manuscripts of the abstracts selected by the Expert Committee were examined by an external review group. This group critically appraised each article and reported back to the Expert Committee. Their evaluation included study design and purpose, directness to the study research question, methodological quality, interventions/outcomes of interest and assessment of potential study biases. They also provided a GRADE ${ }^{16}$ profile of the reviewed articles to use for assigning a grade of evidence. The assigned grade for each study was based on criteria for assigning grade of evidence ${ }^{17}$ (Appendix 3) from the GRADE Working Group. Range for the quality of evidence is from very low to high. Upon consultation with the critical appraisers, it was agreed that all observational studies would receive the same initial ranking of low as stated in Appendix 3. Articles with high directness to the review question were used to develop the recommendations. The quality of the supporting evidence was used to determine the grade for the recommendations (Appendix 4). ${ }^{18,19}$ The Expert Committee met in person to review the critically appraised articles and to formulate and grade the recommendations. According to predetermined terms of reference, consensus was required with respect to the wording and grading of each recommendation. The key evidence from the 15 articles that were critically appraised is summarized in Appendix 5. (One article, a qualitative systematic review ${ }^{20}$ is not included in Appendix 5, as it did not provide independent evidence.) The recommendations in this guideline are meant to reinforce and complement standards of practice currently recommended by CFCP and CPS (Table 1).

The final guideline document was approved by the relevant governing bodies of the Canadian Ophthalmological Society, the Canadian Association of Paediatric Ophthalmology and Strabismus, and the Canadian Association of Optometrists.

NATURAL HISTORY OF REFRACTIVE ERROR, AMBLYOPIA, AND STRABISMUS

Visual impairment can affect 1 to $7 \%$ of children, depending on the definition..$^{21,22}$ Some studies report an even higher prevalence of vision disorders in childhood..$^{23}$ The most frequent and easily corrected ocular problems, by far, are refractive errors. ${ }^{24-26}$ Refractive errors resulting in anisometropia are the most common risk factor for amblyopia.

\section{Refractive error}

Refractive error is a defect in the ability of the eye to focus on an image accurately. Uncorrected refractive errors may be responsible for as much as $69 \%$ of childhood visual impairment. ${ }^{27}$ Refractive errors result in decreased vision because the image of regard is not focused on the retina. If the axial length of the eye is too short, hyperopia results, whereas if the axial length of the eye is too long, myopia results. If the refracting power of the eye is different in one meridian compared with another, astigmatism results. Depending on the degree of refractive error and the age of the child, uncorrected refractive errors could be potentially amblyogenic. ${ }^{6}$

\section{Amblyopia}

Amblyopia is defined as decreased vision, not correctable by glasses, in an otherwise healthy eye. Prevalence in childhood is estimated to range from 1 to $3 \%$, depending on the definition, and is the leading cause of monocular vision loss between age 20 and 70 years. ${ }^{28-33}$ Risk factors include prematurity, neurological disorders, genetic syndromes and positive family history. ${ }^{6,22} \mathrm{~A}$ diagnosis of amblyopia is made when there is a 2 -line difference in bestcorrected vision between eyes. Bilateral amblyopia is considered vision worse than 20/40 in the better seeing eye at $\geq 4$ years of age, or worse than $20 / 50$ at $\leq 3$ years of age. ${ }^{6,33}$ The opposite eye can have subtle deficits. ${ }^{34,35}$ Amblyopia 
is caused by visual deprivation in the amblyopic eye in the ocular developmental period - generally accepted to be until the age of 10 years, although some studies suggest later - leading to structural abnormalities in the brain. ${ }^{36}$ (Newer studies have challenged the concept of a complete loss of plasticity in the adult brain, ${ }^{37,38}$ suggesting that vision can be improved after the end of the conventional critical ocular development period; ${ }^{39-43}$ however, early intervention may still result in better vision outcomes. ${ }^{44}$ ) Amblyopia can result from anisometropia, strabismus or from deprivation due to an obstruction of the visual axis (e.g. media opacity, obstruction from lid). The remainder of the eye and visual pathway is normal. Approximately $40 \%$ of amblyopes have anisometropia, $40 \%$ have strabismus and $20 \%$ have a combined mechanism. A small proportion have obstruction of the visual axis. ${ }^{45}$ Anisometropia is an unequal refractive error in each eye, resulting in relative optical defocus. Hyperopic (far-sighted) anisometropia is particularly amblyogenic. High isometropia (equal, but high refractive error) can be amblyogenic in bilateral cases. ${ }^{46}$ A recent pooled report from 2 of the largest population-based pediatric eye disease studies provides estimates of risk of amblyopia with various levels of refractive error and types of strabismus. ${ }^{21}$

Amblyopia is the second most treatable ocular disease (after refractive error), if detected and treated early.44,47-50 Overall the benefits of screening and treatment where disease is uncovered outweigh any harm and cost. ${ }^{20,51-53}$ Indeed, treating amblyopia has been shown to be one of the most cost-effective medical procedures in the world. . $^{5,55}$ Untreated or insufficiently treated amblyopia may result in life-long impairment in visual function and quality of life. Treatment fails in more than $20 \%$ of cases, ${ }^{45}$ and amblyopia can recur after treatment in as many as $25 \%$ of cases. ${ }^{56,57}$ Earlier diagnosis may mean more successful treatment.

\section{Strabismus}

Strabismus results when the eyes are not aligned. It deprives the visual cortex of simultaneous input from corresponding retinal areas, leading to rivalry and suppression of the input from the non-dominant eye. The result is amblyopia in as many as $50 \%$ of cases of strabismus. ${ }^{58,59}$ Treatment of strabismic amblyopia consists of penalizing the "good" eye, although there are newer behavioural therapies - including dichoptic training and perceptual learning $^{60,61}$ - that hold some promise.

\section{VISION SURVEILLANCE IN PRIMARY CARE}

Family physicians, general pediatricians and other primary care practitioners in Canada use the Rourke Baby Record $^{8}$ or the ABCDaire 9 (in Quebec) to guide their routine health surveillance and examinations of infants and children. Both are based on best evidence and consensus by experts. Specific elements of the eye exam are found in Table 1. The recommendations in this guideline document are meant to reinforce and complement these standards of practice.

\section{Screening}

A summary of Canadian vision screening recommendations is shown in Tables 1 and 2 , $^{1-9,62}$ and highlights the fact that Canadian healthcare professionals are confronted with inconsistent recommendations. A 2013 survey assessed adherence of family physicians and pediatricians in Ontario to the vision screening guidelines for children as recommended by the CPS and the Rourke Baby Record. From a total of 3000 mailed surveys, 719 completed surveys were included in the analysis (23.5\% response rate). Vision screening at every well child visit was reported to be performed by $65 \%$ of family physicians/general practitioners and $52 \%$ of general pediatricians. Red reflex was reported to be checked by $94 \%$ of physicians in children $<3$ years of age, but only by $25 \%$ for children $>3$ years of age. Thirty-seven percent of all physicians reported never performing a visual acuity test in any age group. ${ }^{63}$

In the context of eye care, screening consists of the summary assessment of visual function and ocular anatomy. Screening is not meant to be diagnostic; suspicious or positive results are referred to the appropriate professional for diagnosis and treatment. ${ }^{64}$ Basic vision screening performed at the well-baby visit by a family physician or pediatrician can identify treatable vision issues at an early stage. ${ }^{3}$ In low-risk, asymptomatic children, vision screening in preschool-aged children is aimed at early disease detection for more prevalent conditions such as amblyopia, strabismus and uncorrected refractive error, as well as for rarer conditions diseases such as retinoblastoma and congenital cataracts. ${ }^{3,62,65}$ These screening procedures may be performed by pediatricians, family physicians or other primary care providers during well-baby/child visits. ${ }^{64,66}$ Screening for amblyopia involves screening for risk factors, as they can be diagnosed before amblyopia itself (i.e. before formal vision can be checked). Screening involves checking for refractive error, strabismus and obstructions to the visual axis. Procedures used to screen for strabismus and amblyopia may include visual acuity testing and the cover/uncover test, while procedures for 
screening for retinoblastoma and congenital cataracts may include red reflex and fundus testing. ${ }^{3,62}$ Techniques for these procedures can be found in the literature., ${ }^{3,62,65,67}$ Patients with a positive screening test should be referred to an eye care professional for further evaluation.

Simple screening (i.e. a family history of vision problems and any baby concerns, as well as red reflex test, observation of eye movement, lids and pupils) is quick and easy to perform, but lacks sensitivity and specificity. ${ }^{20,51}$ More rigorous testing is time-consuming and resource-intensive, but provides better sensitivity and specificity. ${ }^{20,51-53} \mathrm{Un}$ corrected refractive error is the most common finding and simplest to correct, but is not easily identified by simple screening. ${ }^{24-26}$ Amblyopia, which affects 2 to $4 \%$ of the population, can by suspected with basic screening, but requires a full assessment prior to proceeding with treatment. ${ }^{47,53}$ Although not conclusive, it would appear that the earlier treatment is initiated the better the final outcome. ${ }^{44,47-50}$

\section{Comprehensive Eye Examinations}

Comprehensive eye exams performed by an optometrist or ophthalmologist allow for a fuller assessment that addresses both amblyogenic and nonamblyogenic, yet treatable, ocular disease. ${ }^{1,3}$ This includes, but is not limited to, refractive errors, subtle strabismus, lid and lacrimal disease, and retinal pathology. ${ }^{1,2,20,51-5,66}$ These examinations are meant to be diagnostic and lead to the management of eye conditions including, but not limited to, amblyopia, strabismus and uncorrected refractive error. ${ }^{1,2,6,66}$ The main components of a comprehensive eye exam consist of the assessment of refractive status, visual acuity, strabismus/binocular vision/ocular motility and ocular anatomy (external and internal). $)^{1,2,6,62,66}$

Examination techniques for strabismus and amblyopia in the pediatric population (ages 0 to 5 years) may include: fixation assessment; visual acuity; cover/uncover tests; red reflex (Bruckner method); corneal light reflexes (Hirschberg reflex); sensory fusion (red filter/Worth 4-dot, etc.); stereopsis testing; and ocular motility testing. Examination techniques for refraction assessment may include: retinoscopy (static or dynamic); manifest (subjective) refraction; and autorefraction (not generally used in this age group). Cycloplegic agents (eye drops that inhibit accommodation temporarily) should be used in conjunction with these techniques. Supplemental examination techniques include pupillary testing, visual field testing, intraocular pressure, colour vision testing, funduscopy and slit lamp or external ocular health assessment., ${ }^{1,6,62,66}$

\section{REVIEW OF THE EVIDENCE AND RATIONALE FOR RECOMMENDATIONS}

The primary goal of the literature review was to find studies that assessed the impact, if any, of vision screening on the prevalence of amblyopia in childhood. Of the 15 key articles included in the summary of findings (Appendix 5), 11 provided evidence related to our study question and recommendations. Performance (quality or efficacy) of screening tests by family physicians, pediatricians, orthoptists, optometrists or ophthalmologists was not explored specifically.

No masked randomized clinical trial has evaluated the effectiveness of vision screening in children aged 0 to 5 years; however, prospective cohort studies have provided consistent and strong evidence that vision screening from 8 to 48 months reduces the prevalence of amblyopia at 7 to 8 years. Four studies from 3 countries (Israel, England and the Netherlands) were directly related to our main research question and were rated as moderate in overall quality. The Israeli study, ${ }^{44}$ was a prospective cohort trial in Haifa that included 808 children who were screened between 1 and 2.5 years of age with a follow-up exam completed at 8 years of age (screening included Hirschberg test [i.e., corneal light reflex test], cover test and retinoscopy without cyclopegia). The children were screened by members of the Bnai-Zion Ophthalmology Department for amblyopia and amblyogenic risk factors. Children $(\mathrm{n}=782)$ in a comparable population, but without early screening, were also examined at 8 years of age. Amblyopia was 2.6 times more likely to be present in the cohort that was not screened ( $2.6 \%$ vs. $1.0 \%$, respectively, $\mathrm{p}=0.0098)$. Children who were not screened also had more severe amblyopia $(1.7 \%$ vs. $0.1 \%$ in screened children, $\mathrm{p}=0.00026$ ).

Two studies in England from the Avon Longitudinal Study of Parents and Children (ALSPAC), also rated as moderate in quality, explored early screening and the prevalence of amblyopia. ${ }^{48,49}$ A randomized trial nested in a prospective cohort compared children who received multiple orthoptic screenings from 8 to 37 months of age (intensive group, $\mathrm{n}=2029$ ) to children who received only one screening at 37 months of age (control group, $\mathrm{n}=1490)$. Amblyopia was less prevalent at 7.5 years of age in the intensive group (1.45\% vs. $2.66 \%$ in the control group, $\mathrm{p}=0.06$ ). A major concern regarding this study is that only $54 \%$ of the initial intensive group and $55 \%$ of 
the control group were assessed at the 7.5-year exam. ${ }^{49}$ The second study, an observational trial nested in the prospective cohort, examined the impact of orthoptic screening offered at ages 4 to 5 years versus no screening. ${ }^{48}$ The prevalence of amblyopia at 7.5 years was $45 \%$ lower in children who received preschool screening than in those who did not ( $1.1 \%$ vs. $2.0 \%$, respectively; $\mathrm{p}=0.052)$. The power of this study was too low to show statistically significant results regarding the prevalence of amblyopia when the data were adjusted for several potentially confounding factors related to amblyopia.

Studies from the Netherlands also explored early and multiple vision screenings in a single birth cohort. Children born in Rotterdam between September 1996 and May 1997 were followed to the age of 7 years. One study, evaluated as moderate in overall quality, examined the effect of multiple screenings from ages 1 to 72 months (2964 of the original Rotterdam Amblyopia Screening Effectiveness Study [RAMSES] cohort) on the prevalence of amblyopia at 7 years. There was a 3.4\% prevalence of amblyopia at 7 years and a dose-response effect with children who attended more screenings having lower rates of amblyopia. ${ }^{47}$ Another report on this same cohort stated that preschool screening from age 3 years contributed most to amblyopia detection. ${ }^{51}$ The authors also reported that refractive error was the most common cause of amblyopia. Neither of these studies included a control group of children who were not screened.

The above studies, from different countries and employing a variety of screening tests at different ages, all reported similar findings: lower prevalence of amblyopia by age 7 to 8 years in screened versus unscreened children and with multiple screenings versus single screenings.

Ascertaining evidence from published studies regarding the best age at which to screen children was more difficult. Additional studies that explored the importance of age at the time of screening were found, but all were evaluated as low in overall study quality. One article from the Netherlands did not show a difference in rate of referral to ophthalmologists or in prevalence of amblyopia between a screened versus an unscreened cohort at the age of 6 to 9 months. ${ }^{68}$ This finding may have reflected a problem with the tests or screeners used, rather than the age of children. Referrals in both groups were based primarily on observed strabismus, and 25 to $50 \%$ of the screeners were found to have inadequately performed the screening tests.

The impact of early referral for treatment on visual acuity outcomes and prevalence of amblyopia was explored in 2 other prospective studies that were evaluated as low in overall study quality. A study of children referred during a screening program in Alaska found that children referred for treatment before 2 years of age had a greater chance of achieving a visual acuity of $6 / 12$; however, this study's results were vulnerable to bias since $<25 \%$ of potential participants were included in the final outcome assessment. ${ }^{50}$ Atkinson and colleagues reported on 2 Cambridge Infant Screening Programs with a focus on children with hyperopia. ${ }^{53}$ The first program screened 3166 children (born from 1981 to 1983) at 7 to 8 months of age with a follow-up between 1 and 3 years of age and visual acuity testing at 4 years of age. The second program screened 5142 children (born from 1992 to 1994 ) at 8 months of age and then administered up to 11 follow-up visits by 7 years of age. Both programs reported a decreased prevalence of amblyopia in hyperopic children with early spectacle wear when evaluated at 4 years of age and 7 years of age, compared with hyperopic children who did not wear spectacles. ${ }^{53}$

Of the 3 cross-sectional studies that were evaluated, all received low or very low overall study quality ratings due to concerns about potential selection bias..$^{31,26,69}$ The studies evaluated as low in overall study quality were from the United States. One study from Tennessee with 5548 children aged 1 to 6 years found a very high prevalence of amblyopia in children with anisometropia (454/724 or $62.7 \%) .{ }^{69}$ Donahue also reported that by age 3 , nearly two-thirds of children with $>1.0$ diopter anisometropia had amblyopia, and the prevalence of amblyopia increased with age among anisometropic children. The Vision in Preschoolers Study found a high prevalence of unilateral amblyopia (296/3869 or $7.7 \%)$ in children aged 3 to 5 years in Head Start programs. ${ }^{26}$ In this group, the increased risk of amblyopia was independently associated with the presence of strabismus and significant refractive errors (e.g. myopia, hyperopia, astigmatism and anisometropia).

A cross-sectional study from Australia was rated as very low in overall study quality, as a large number of children were excluded from the study due to low visual acuity testability. ${ }^{31}$ This study, part of the Sydney Paediatric Eye Study, recruited 2461 children between the ages of 6 and 72 months, but results were reported for only 1422 of them. The prevalence of amblyopia was found to be $27 / 1422$ (1.9\%) and was significantly associated with hyperopia, astigmatism, anisometropia and strabismus. ${ }^{31}$ 
In summary, there is very strong evidence from well-conducted prospective studies that cohorts of children screened at an early age will have a lower prevalence and severity of amblyopia at age 7 to 8 years, compared with unscreened cohorts. ${ }^{44,47-49,51}$ The age at which the screenings in these studies took place varied, but it is known from other studies that the earlier the detection and treatment of potential risk factors for amblyopia the better the visual outcomes. ${ }^{50,53}$ Risk factors that must be detected include refractive errors, anisometropia and strabismus. ${ }^{26,31,69}$

Based on this review, the Expert Committee concluded that, in addition to routine screening by a primary health care professional, a comprehensive eye examination by an individual with the expertise to detect risk factors for amblyopia - such as an ophthalmologist or optometrist - is recommended in early childhood. Overall, the findings support the importance of early detection of amblyopia prior to 36 months and no later than 48 months of age via screening with at least 1 comprehensive eye exam before age 5 years.

\section{RECOMMENDATIONS}

- Routine age-appropriate screening as recommended by Rourke and ABCDaire (red reflex test, cover/ uncover test, and visual acuity) of infants and children by a primary healthcare provider or pediatrician should continue. ${ }^{8,9}$

- If an infant or child is identified with an abnormality, they should be referred to the appropriate eye care professional.

- In addition to age-appropriate screening, children aged 0 to 5 years should undergo ocular assessment by an individual with the expertise to detect risk factors for amblyopia. [1B $\left.{ }^{44,47-49}\right]$

- Ideally, the ocular assessment should occur by age 3 years. [1B $\left.{ }^{44,47-49}\right]$

- The ocular assessment should include refraction and ocular motility evaluation. [1B $\left.\mathrm{B}^{44,47-49}\right]$

\section{LIMITATIONS}

The main limitation to the implementation of this guideline may be access and the increased resources required to sustain such a screening process. Further efforts should thus focus on advocating that children have access to oculovisual assessments that detect treatable eye conditions.

\section{CONCLUSIONS}

Vision screening performed by primary healthcare providers during routine well-baby/child visits and scheduled vaccinations have been - and will continue to be - an essential part of the detection of ocular disease. Obtaining an appropriate history while performing an assessment of the red reflex and examination of the external adenexa provides an opportunity for the early detection of not only amblyogenic pathology, but also other potentially visionthreatening (e.g. cataracts, glaucoma) and life-threatening diseases (e.g. retinoblastoma). However, this early detection potential is limited and a full oculovisual assessment is also recommended prior to the child entering the school system. Although comprehensive eye exams are possible from birth by certain eye care professionals by adapting techniques, by age 3 it is expected that the child may be able to cooperate in a complete oculovisual assessment. This would include visual acuity testing, ocular motility evaluation, slit lamp exam, dilated fundus exam and cycloplegic refraction. If amblyopia, strabismus or other eye pathology is detected or suspected that is beyond the scope of the eye care professional examining the patient, a referral to the appropriate specialist can be made, allowing treatment to be initiated in a timely fashion.

\section{ACKNOWLEDGMENTS}

This article is being simultaneously published in the Canadian Journal of Ophthalmology. The Expert Committee acknowledge the assistance of Cynthia Lank, BSc, Project Manager and Executive Editor, and Mona Frantzke, BSc MLS, Medical Librarian. In addition, they acknowledge the independent critical appraisal of the evidence by the following: Ya-Ping Jin, MD PhD, Department of Ophthalmology and Vision Sciences, University of Toronto; Andrei-Alexandru Szigiato, Hon BSc MD, Research Fellow, Glaucoma and Advanced Anterior Segment Surgery, Department of Ophthalmology and Vision Sciences, University of Toronto; Alex Lai Chi Tam, MSc, Department of Ophthalmology and Vision Sciences, University of Toronto; Sophia Liu, BMSc, Faculty of Medicine, University of Toronto. 
FUNDING

This project was jointly funded by the Canadian Ophthalmological Society and the Canadian Association of Optometrists. No industry funding was sought or provided.

DISCLOSURES

Expert Committee members disclosed any and all potential conflicts/dualities of interest for the previous 2 years (regardless of whether these relationships had any bearing on the guideline topic).

BER: No affiliation (financial or otherwise) with a commercial organization.

WTD: No affiliation (financial or otherwise) with a commercial organization.

BT: No affiliation (financial or otherwise) with a commercial organization.

JAG: Participation in a clinical trial supported by Vertex.

LN: No affiliation (financial or otherwise) with a commercial organization.

ARL: No affiliation (financial or otherwise) with a commercial organization. 
Table 1: Current Canadian recommendations for vision screening in children

\begin{tabular}{|l|l|l|l|l|}
\hline \multicolumn{1}{|c|}{ Organization } & \multicolumn{1}{|c|}{ COS } & \multicolumn{1}{c|}{ CAO } & \multicolumn{1}{c|}{ CFPC } \\
\hline $\begin{array}{l}\text { Key } \\
\text { recommendations }\end{array}$ & NA & $\begin{array}{l}\text { CPfants and toddlers should } \\
\text { undergo their first eye } \\
\text { examination between the } \\
\text { ages of 6 and 9 months; } \\
\text { preschool children should } \\
\text { undergo at least 1 eye } \\
\text { examination between the } \\
\text { ages of 2 and 5 years. }\end{array}$ & $\begin{array}{l}{ }^{1} \\
\text { ageck red reflex for } \\
\text { serious ocular diseases } \\
\text { such as retinoblastoma and } \\
\text { cataracts. } \\
\text { Corneal light reflex/cover- } \\
\text { uncover test and inquiry for } \\
\text { strabismus. } \\
\text { Check visual acuity at age 3 } \\
\text { to 5 years. }{ }^{8,9}\end{array}$ & $\begin{array}{l}\text { Check red reflex for } \\
\text { serious ocular diseases } \\
\text { such as retinoblastoma and } \\
\text { cataracts. } \\
\text { Corneal light reflex/cover- } \\
\text { uncover test \& inquiry for } \\
\text { strabismus } \\
\text { Check visual acuity at age } \\
3 \text { to 5 years. } \\
\text { Routine comprehensive } \\
\text { professional eye } \\
\text { examinations of healthy } \\
\text { children with no risk factors } \\
\text { have no proven benefit. }\end{array}$ \\
\hline
\end{tabular}

$\mathrm{CAO}=$ Canadian Association of Optometrists, CFPC = College of Family Physicians of Canada, COS = Canadian Ophthalmological Society, CPS = Canadian Paediatric Society

Table 2: Current published vision screening guidelines*

\begin{tabular}{|c|c|c|c|c|c|c|c|c|c|c|}
\hline Guideline & $\begin{array}{c}0-3 \\
\text { months }\end{array}$ & $\begin{array}{c}3-6 \\
\text { months }\end{array}$ & $\begin{array}{c}6-9 \\
\text { months }\end{array}$ & 3 years & $\begin{array}{c}2-5 \\
\text { years }\end{array}$ & $\begin{array}{c}6-19 \\
\text { years }\end{array}$ & $\begin{array}{l}20-39 \\
\text { years }\end{array}$ & $\begin{array}{l}40-64 \\
\text { years }\end{array}$ & $\begin{array}{l}56-65 \\
\text { years }\end{array}$ & $\begin{array}{c}>65 \\
\text { years }\end{array}$ \\
\hline $\begin{array}{l}\text { AAP } \\
2003^{62}\end{array}$ & & & & Screen & & Screen & \multicolumn{4}{|l|}{ NA } \\
\hline $\begin{array}{l}\text { AAPOS } \\
2012^{6,7}\end{array}$ & \multicolumn{5}{|l|}{ Screen } & $\begin{array}{l}\text { Every } \\
1 \text { to } 2 \\
\text { years }\end{array}$ & \multicolumn{4}{|l|}{ NA } \\
\hline $\begin{array}{l}\text { CADTH } \\
2007^{4}\end{array}$ & \multicolumn{4}{|c|}{$\begin{array}{l}\text { Preschool vision screening programs } \\
\text { varied from province to province, from } \\
\text { public health nurse to full optometric } \\
\text { exam; none shown to be superior. }\end{array}$} & Screen & \multicolumn{5}{|l|}{ NA } \\
\hline CAO $2012^{1}$ & & & $\begin{array}{l}\text { Eye } \\
\text { exam }\end{array}$ & & $\begin{array}{l}\text { Eye } \\
\text { exam }\end{array}$ & Annually & $\begin{array}{l}\text { Every } \\
2 \text { to } 3 \\
\text { years }\end{array}$ & $\begin{array}{l}\text { Every } 2 \\
\text { years }\end{array}$ & $\begin{array}{l}\text { Every } 2 \\
\text { years }\end{array}$ & Annually \\
\hline $\operatorname{Cos} 2007^{2}$ & NA & & & & & & $\begin{array}{l}\text { At least } \\
\text { every } 10 \\
\text { years }\end{array}$ & $\begin{array}{l}\text { At least } \\
\text { every } 5 \\
\text { years }\end{array}$ & $\begin{array}{l}\text { At least } \\
\text { every } 3 \\
\text { years }\end{array}$ & $\begin{array}{l}\text { At least } \\
\text { every } 2 \\
\text { years }\end{array}$ \\
\hline CPS $2009^{3}$ & Screen & & Screen & & Screen & Screen & NA & & & \\
\hline $\begin{array}{l}\text { USPSTF } \\
2017^{5}\end{array}$ & & Screen & & & Screen & NA & & & & \\
\hline
\end{tabular}

* Please see original documents for full details. This table is intended to highlight the differences in scope and recommendations of various guidelines, and is not intended to summarize completely each document.

AAP = American Academy of Pediatrics, AAPOS = American Association for Pediatric Ophthalmology and Strabismus, $\mathrm{CADTH}=$ Canadian Agency for Drugs and Technology in Health, CAO = Canadian Association of Optometrists, COS = Canadian Ophthalmological Society, CPS $=$ Canadian Paediatric Society, NA $=$ These guidelines did not address these age groups, USPSTF = United States Preventive Services Task Force 
Index test: (1)

Vision Tests[Mesh:noexp] OR Diagnostic Techniques, Ophthalmological[MAJR:noexp] OR ((Refraction, Ocular[MAJR] OR Visual Acuity[MAJR]) AND (exam*[tw] OR test[tw] OR tests[tw] OR assessment*[tw]))

Index screening: (2)

Vision Screening[Mesh] OR ((screening[tw] OR Mass Screening[Mesh]) AND (eye[tw] OR vision[tw] OR ocular[tw] OR visual[tw] OR ophthalmic [tw]))

Target condition: (3)

Amblyopia[Mesh] OR amblyopia[tw] OR Strabismus[Mesh] OR strabismus[tw] OR Refractive Errors[Mesh] OR refractiveerror*[tw] OR refractive-disorder*[tw] OR lazy-eye*[tw] OR squint [tw] OR cross-eye*[tw] OR astigmatism[tw] OR presbyopia[tw] OR myopia[tw] OR hyperopia[tw] OR anisometropia[tw] OR ocular-alignment[tw] OR Vision Disorders/ diagnosis[MAJR:noexp] OR Eye Diseases/diagnosis[MAJR:noexp]

Context applicable keywords: (4)

Evidence-Based Practice[Mesh] OR evidence-based[tw] OR Early Diagnosis[Mesh:noexp] OR early-diagnosis[tw] OR earlydiagnostic[tw] OR undetected[tw] OR uncorrected[tw] OR visual-impairment[tw] OR "Referral and Consultation"[Mesh] OR Early Medical Intervention[Mesh] OR Risk Factors[Mesh] OR Age of Onset[Mesh] OR Time Factors[Mesh] OR Advisory Committees[Mesh] OR guideline[pt] OR practice-guideline[pt] OR “Consensus Development Conference”[pt] OR guideline*[tw] OR consensus[tw] OR recommendation*[tw] OR Ophthalmology[Mesh:noexp] OR Optometry[Mesh:noexp] OR optometrist*[tw] OR ophthalmologist*[tw] OR pediatrician[tw] OR paediatrician[tw] OR Primary Health Care[Mesh] OR ((comprehensive[tw] OR routine[tw] OR periodic[tw] OR population-based[tw] OR whole-population[tw] OR universal[tw] OR gold-standard[tw] OR Asymptomatic Diseases[Mesh] OR asymptomatic[tw] OR schedule[tw]) AND (eye[tw] OR vision[tw] OR ocular[tw] OR visual[tw] OR ophthalmic[tw]))

Target age group: (5)

Child, Preschool[Mesh] OR Infant[Mesh] OR preschool[tw] OR pre-school[tw] OR kindergarten[tw] OR kindergarden[tw] OR Pediatrics[Mesh] OR pediatric*[tw] OR paediatric*[tw] OR children[tw]

Limits: (6)

(English[lang] OR French[lang]) AND (“1995/01/01”[PDAT] : “3000/12/31”[PDAT])

Final Medline search

(1 OR 2) AND (3 OR 4) AND 5 AND 6

The Embase Search was the same as the Medline search, but without the Mesh terms and excluding Medline records.

\section{APPENDIX 2: Literature search strategy: Inclusion and exclusion criteria}

Inclusion criteria: Studies of children with interventions completed from 0 to 5 years of age; well-conducted clinical trials and observational studies; studies of amblyopia, amblyogenic risk factors, and refractive error; research articles published in peer-reviewed journals written in English or French; studies performed in primary care and population-based settings; studies of screening tests typically available in primary care settings (e.g. visual acuity tests, red reflex, and cover test) or examination techniques used by optometrists and ophthalmologists (e.g. retinoscopy, etc.); studies with the following outcomes: improved visual acuity, reduced amblyopia, improved school performance, and quality of life.

Exclusion criteria: Studies in children aged $\geq 6$ years; articles on ocular complications of other diseases (e.g. diabetes); articles on subsets of patients with known ocular diseases (e.g. diabetes, glaucoma, retinopathy of prematurity, age-related macular degeneration); articles not focused on visual outcomes; articles evaluating the utility or cost-effectiveness of a particular screening digital or instrument-based tool (e.g. teleophthalmology, hand-held screening devices, digital screening devices, Retinomax autorefractor); articles evaluating screening programs (e.g. school-based, long-term care institution-based); articles addressing treatment or patient adherence to treatment; articles from countries with a significantly different ethnic composition and/or healthcare system than Canada's; articles describing existing programs; articles describing jurisdictional policies; opinion pieces or editorials; chart reviews; articles in languages other than French or English; articles on vision loss prevention; articles directed toward school nurses or orthoptists; policy papers; articles on healthcare resource or manpower issues; articles on uptake of guideline recommendations; articles on focus group or survey data; and articles considered to be outdated. 
APPENDIX 3: Criteria for assigning grade of evidence (based on GRADE guidelines) ${ }^{17}$

\begin{tabular}{|c|c|}
\hline Types of evidence & $\begin{array}{l}\text { - } \text { Randomized trial = high } \\
\text { - Observational study = low } \\
\text { - } \text { Any other evidence = very low }\end{array}$ \\
\hline Decrease* grade if... & $\begin{array}{l}\text { - Serious or very serious limitation to study quality } \\
\text { - Important inconsistency } \\
\text { - Some or major uncertainty about directness } \\
\text { - Imprecise or sparse data } \\
\text { - High probability of reporting bias }\end{array}$ \\
\hline Increase grade if... & $\begin{array}{l}\text { - Strong evidence of association - significant relative risk of }>2(<0.5) \text { based on consistent evidence } \\
\text { from two or more observational studies, with no plausible confounders }(+1) \\
\text { - Very strong evidence of association - significant relative risk of }>5(<0.2) \text { based on direct evidence } \\
\text { with no major threats to validity }(+2) \\
\text { - Evidence of a dose response gradient }(+1) \\
\text { - All plausible confounders would have reduced the effect }(+1)\end{array}$ \\
\hline Range & $\begin{array}{l}\text { - High-quality evidence } \\
\text { - Moderate-quality evidence } \\
\text { - Low-quality evidence } \\
\text { - Very low-quality evidence }\end{array}$ \\
\hline
\end{tabular}

* Each quality criteria can reduce the quality by 1 or, if very serious, by 2 levels.

APPENDIX 4: Grading of recommendations according to the strength of the recommendation (1-2) with implications, and the quality of the evidence (confidence in estimate of effect, $A-C$ ); based on GRADE Guidelines ${ }^{18,19}$

\begin{tabular}{|c|c|c|}
\hline $\begin{array}{l}\text { Grade of recommendation } \\
\text { (Implication) }\end{array}$ & Estimate of Effect & Evidence Quality \\
\hline $\begin{array}{l}\text { 1A: Strong recommendation, } \\
\text { high-quality evidence } \\
\text { (Applies to most patients) }\end{array}$ & $\begin{array}{l}\text { Very strong evidence of } \\
\text { significant relative risk. }\end{array}$ & $\begin{array}{l}\text { Evidence from }>1 \text { well-performed RCT, or overwhelming } \\
\text { evidence in some other form. Further research is unlikely } \\
\text { to change confidence in the estimates of effect. }\end{array}$ \\
\hline $\begin{array}{l}\text { 1B: Strong recommendation, } \\
\text { moderate-quality evidence } \\
\text { (Applies to most patients) }\end{array}$ & $\begin{array}{l}\text { Strong evidence of significant } \\
\text { relative risk. }\end{array}$ & $\begin{array}{l}\text { Evidence from RCTs with important limitations } \\
\text { (inconsistent results, methodological flaws, or } \\
\text { imprecision), or very strong evidence of some other } \\
\text { research design. Further research (if performed) may } \\
\text { change the estimate of effect. }\end{array}$ \\
\hline $\begin{array}{l}\text { 1C: Strong recommendation, } \\
\text { low-quality evidence } \\
\text { (Applies to most patients) }\end{array}$ & $\begin{array}{l}\text { Benefits appear to outweigh } \\
\text { risks and burdens, or vice } \\
\text { versa. }\end{array}$ & $\begin{array}{l}\text { Evidence from observational studies, unsystematic clinical } \\
\text { experience, or RCTs with serious flaws. Further research is } \\
\text { likely to change the estimate of effect. }\end{array}$ \\
\hline $\begin{array}{l}\text { 2A: Weak recommendation, } \\
\text { high-quality evidence } \\
\text { (Does not apply to all patients) }\end{array}$ & $\begin{array}{l}\text { Benefits closely balanced with } \\
\text { risks and burdens. }\end{array}$ & $\begin{array}{l}\text { Evidence from }>1 \text { well-performed RCT, or overwhelming } \\
\text { evidence of some other form. Further research is unlikely } \\
\text { to change confidence in the estimate of effect. }\end{array}$ \\
\hline $\begin{array}{l}\text { 2B: Weak recommendation, } \\
\text { moderate-quality evidence } \\
\text { (Alternative approaches may } \\
\text { be better) }\end{array}$ & $\begin{array}{l}\text { Benefits closely balanced with } \\
\text { risk and burdens, with some } \\
\text { uncertainty in the estimates of } \\
\text { benefits, risk and burdens. }\end{array}$ & $\begin{array}{l}\text { Evidence from RCTs with important limitations } \\
\text { (inconsistent results, methodological flaws, or } \\
\text { imprecision), or very strong evidence of some other } \\
\text { research design. Further research (if performed) may } \\
\text { change the estimate of effect. }\end{array}$ \\
\hline $\begin{array}{l}\text { 2C: Weak recommendation, } \\
\text { low-quality evidence } \\
\text { (Alternative approaches may } \\
\text { be better) }\end{array}$ & $\begin{array}{l}\text { Uncertainty in the estimates } \\
\text { of benefits, risks and burdens; } \\
\text { benefits may be closely } \\
\text { balanced with risks and } \\
\text { burdens. }\end{array}$ & $\begin{array}{l}\text { Evidence from observational studies, unsystematic clinical } \\
\text { experience, or RCTs with serious flaws. Further research is } \\
\text { likely to change the estimate of effect. }\end{array}$ \\
\hline
\end{tabular}

$\mathrm{RCT}=$ randomized controlled trial 


\begin{tabular}{|c|c|c|c|c|c|}
\hline & 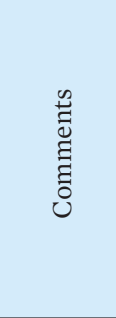 & 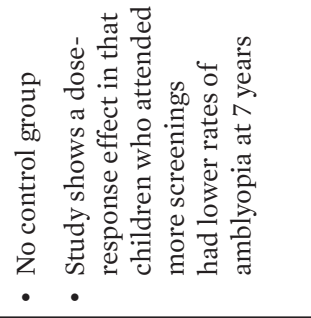 & 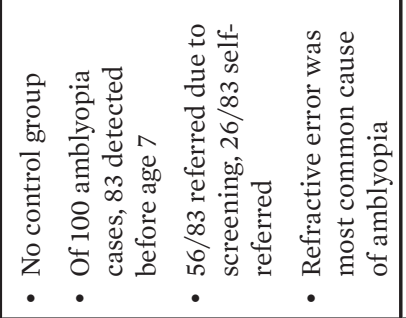 & 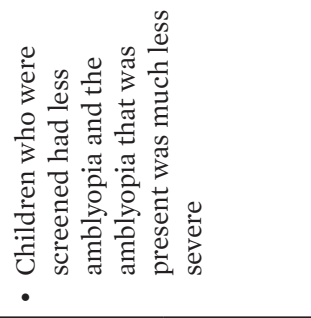 & 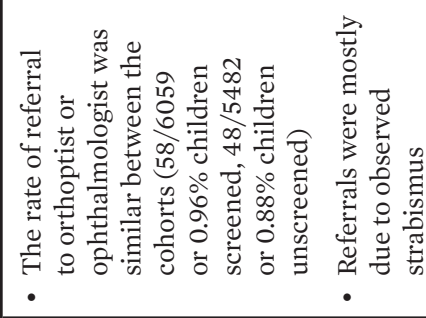 \\
\hline & 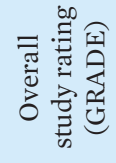 & 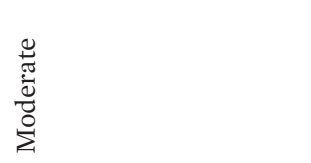 & 䓵 & 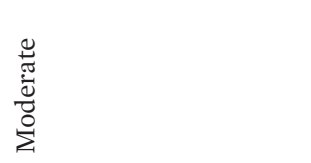 & 菅 \\
\hline & 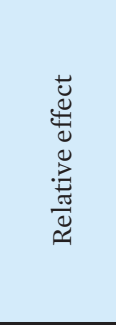 & & 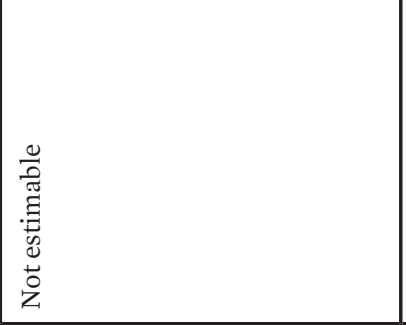 & 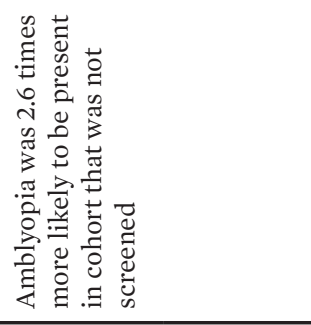 & \\
\hline 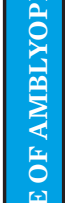 & 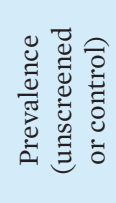 & 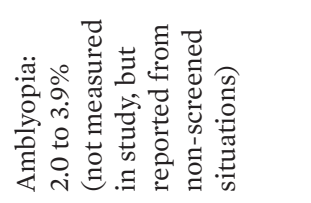 & & 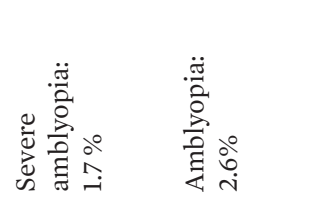 & 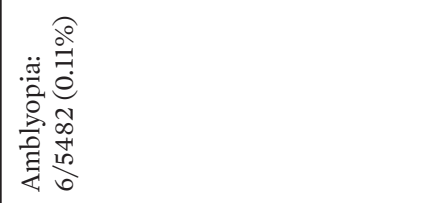 \\
\hline 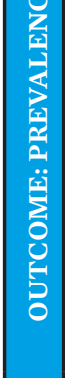 & 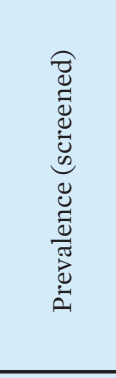 & 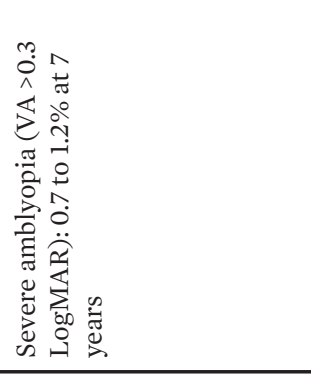 & 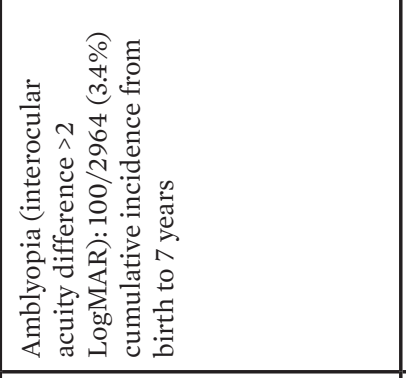 & 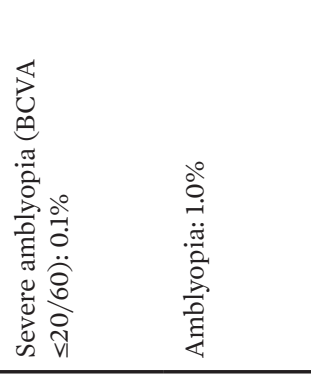 & 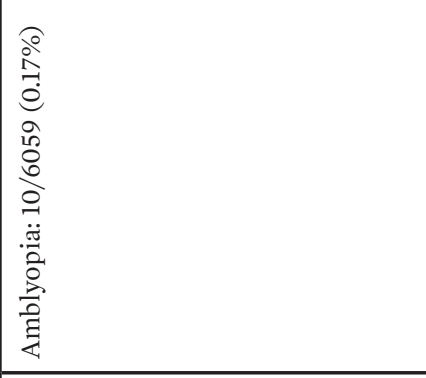 \\
\hline & 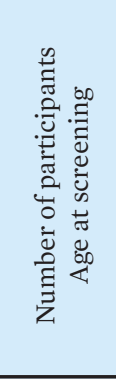 & 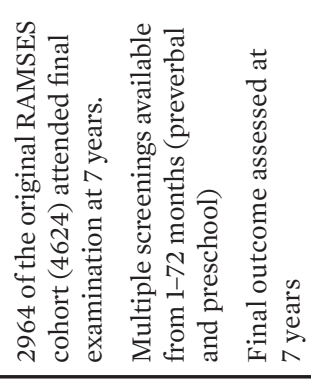 & 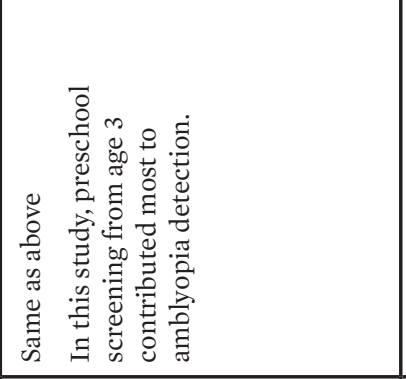 & 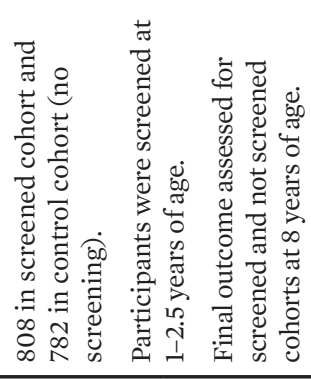 & 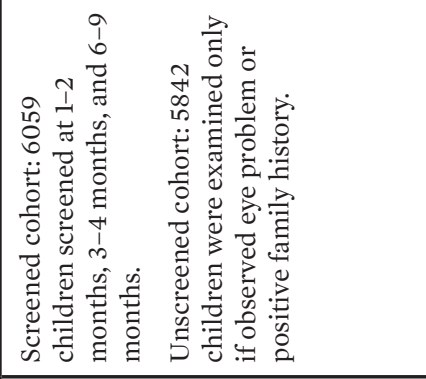 \\
\hline & 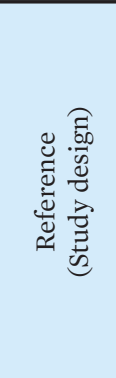 & 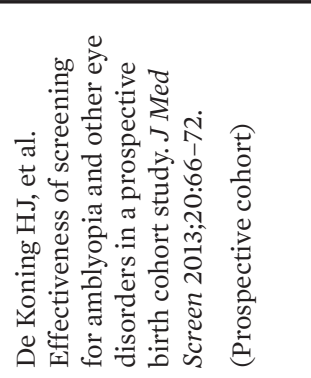 & 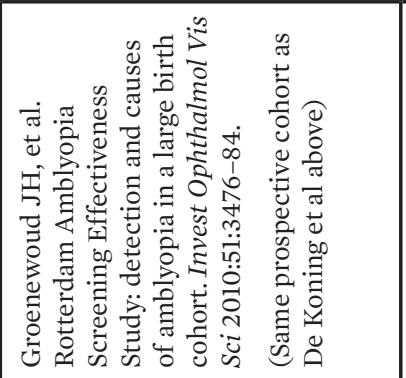 & 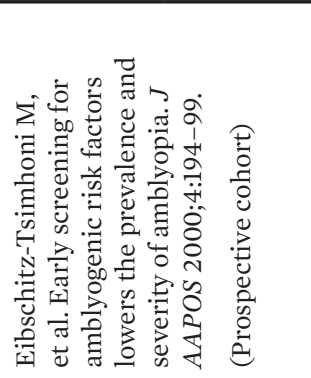 & 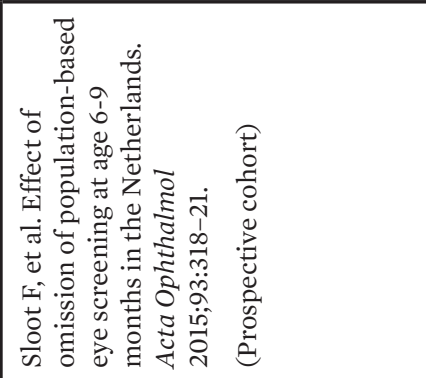 \\
\hline
\end{tabular}




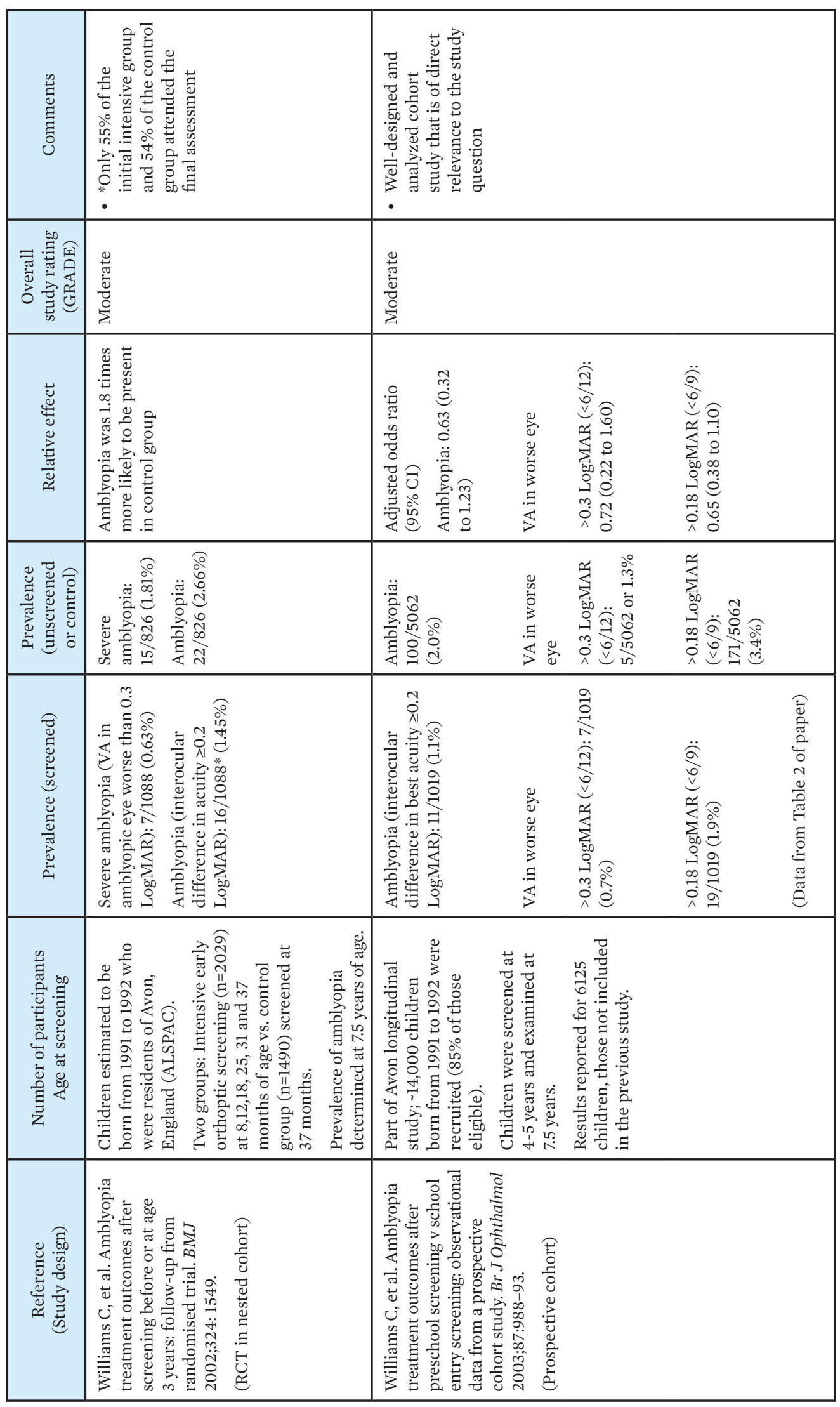




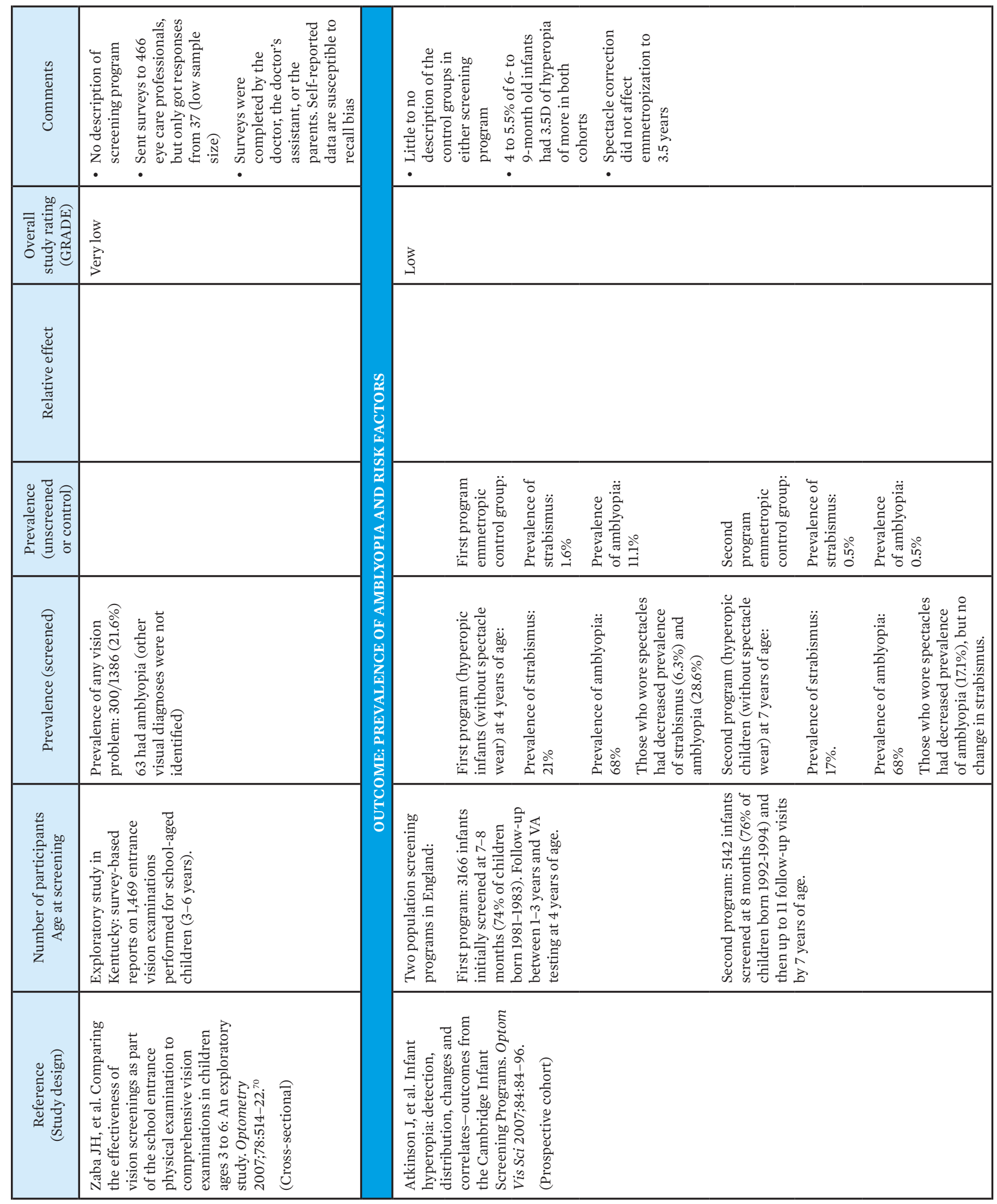




\begin{tabular}{|c|c|c|c|c|c|}
\hline 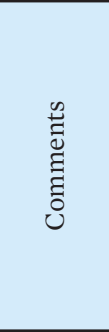 & 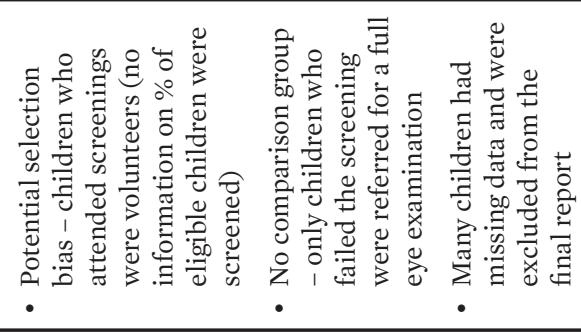 & 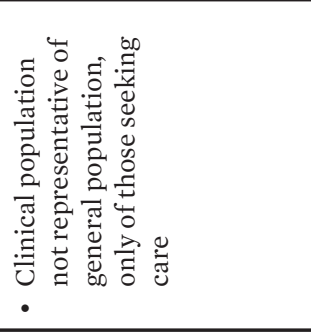 & 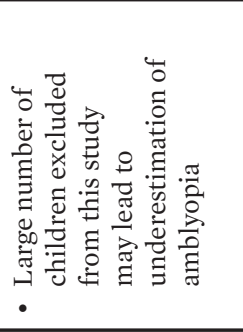 & & \\
\hline 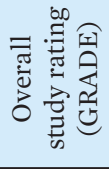 & 艿 & 容 & & & \\
\hline 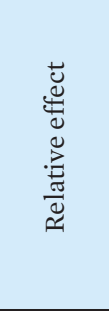 & & & 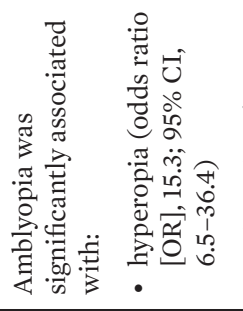 & 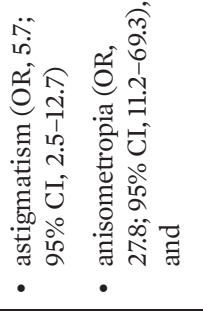 & 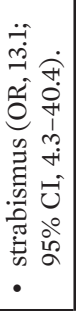 \\
\hline 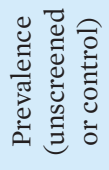 & & & & & \\
\hline 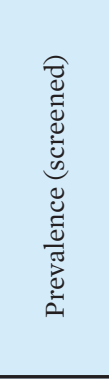 & 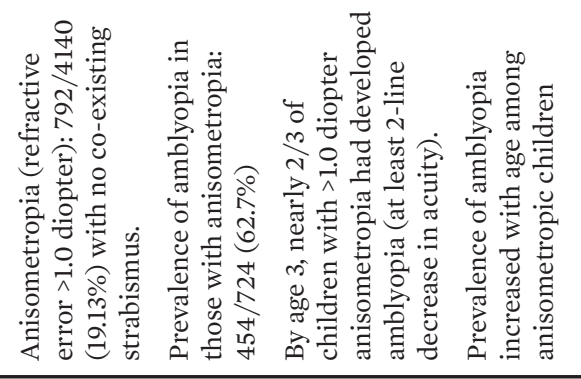 & 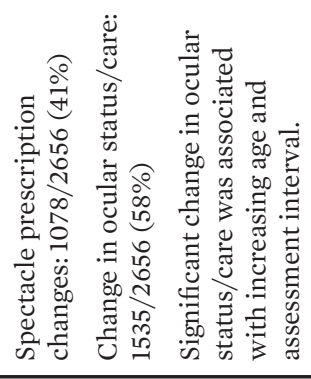 & 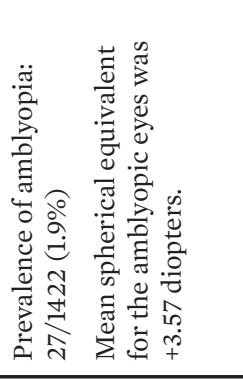 & & \\
\hline 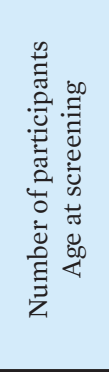 & 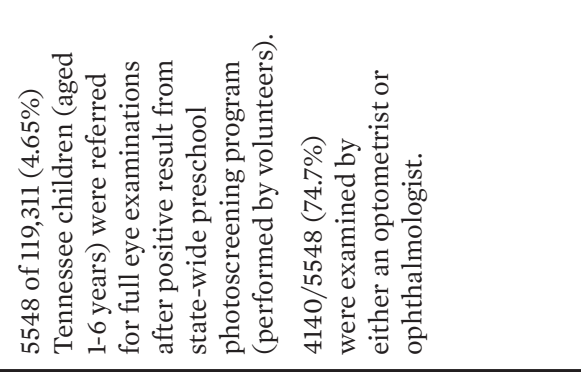 & 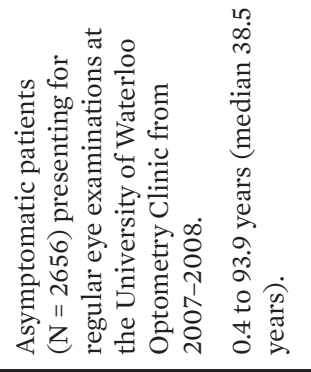 & 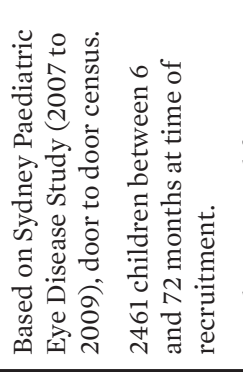 & 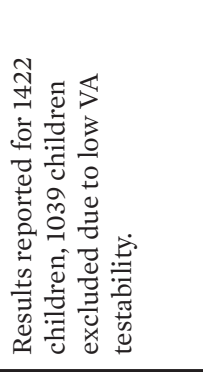 & \\
\hline 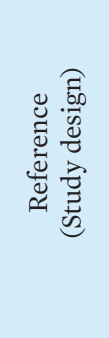 & 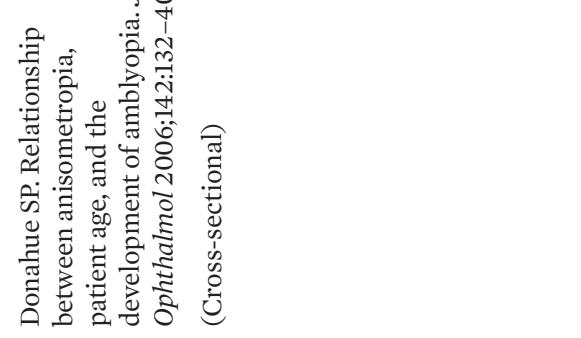 & 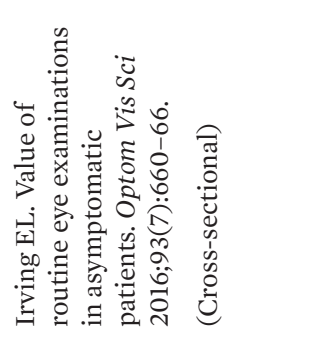 & 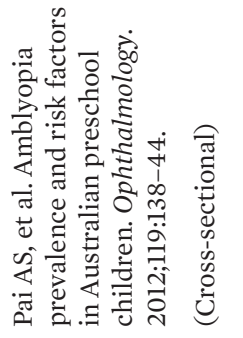 & & \\
\hline
\end{tabular}




\begin{tabular}{|c|c|c|c|}
\hline 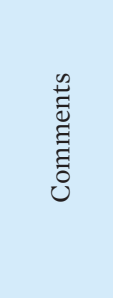 & 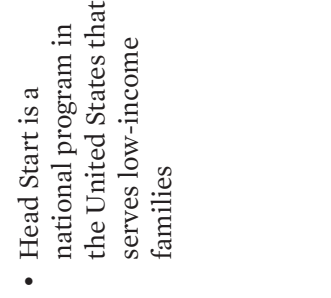 & 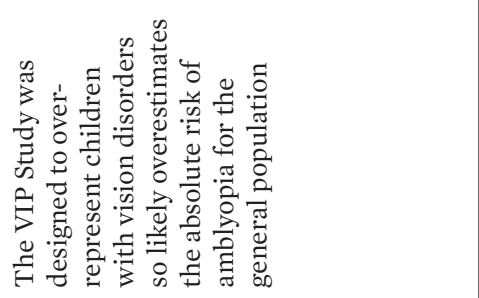 & 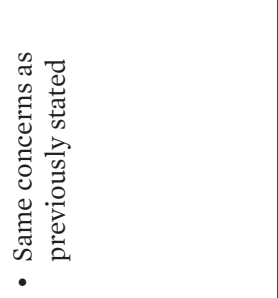 \\
\hline 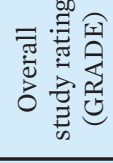 & కై & 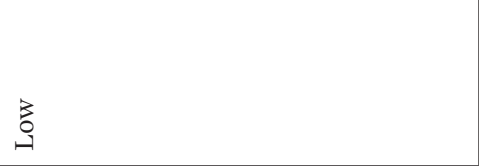 & 䓂 \\
\hline 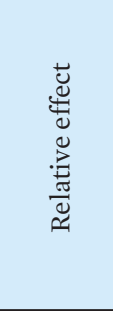 & 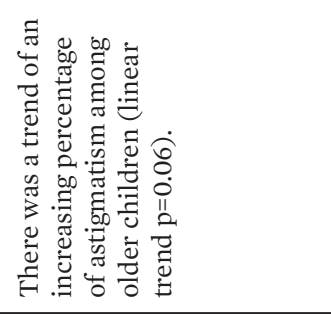 & 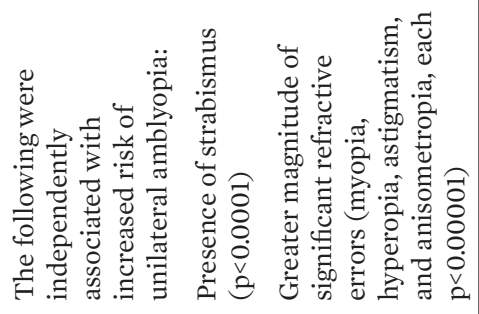 & \\
\hline 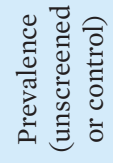 & & & \\
\hline 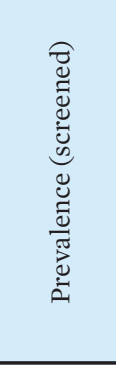 & 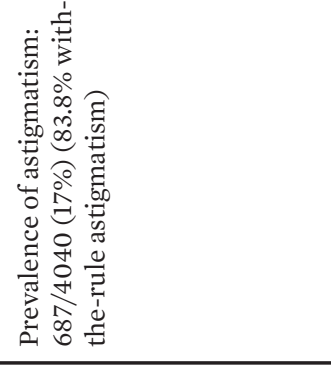 & 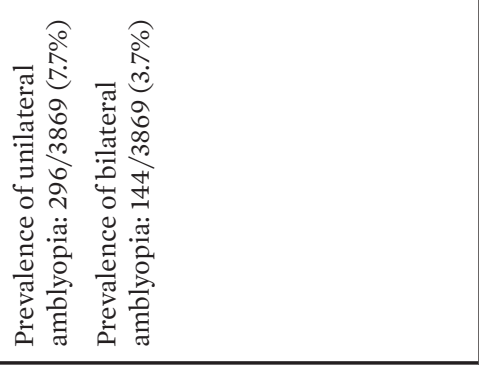 & 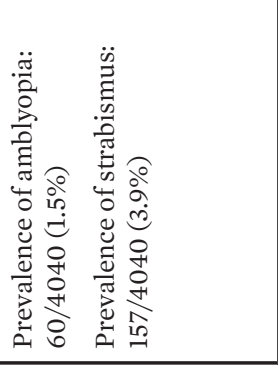 \\
\hline 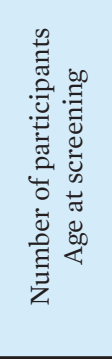 & 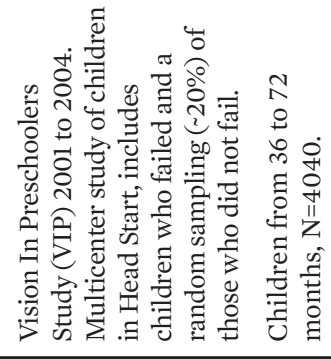 & 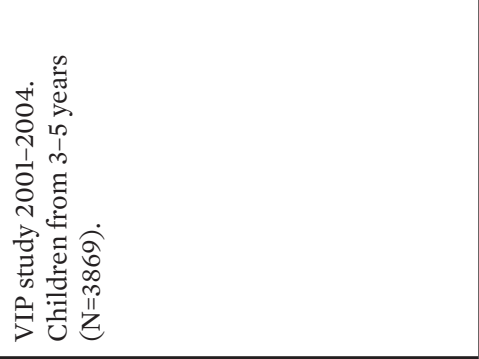 & 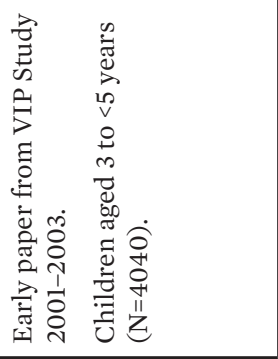 \\
\hline 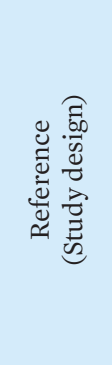 & 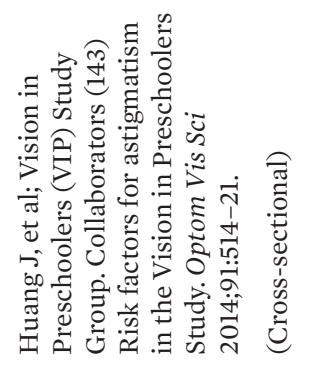 & 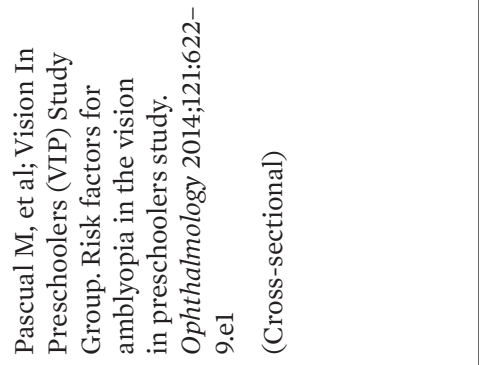 & 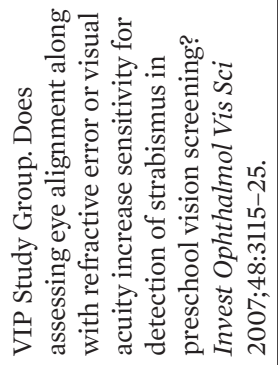 \\
\hline
\end{tabular}



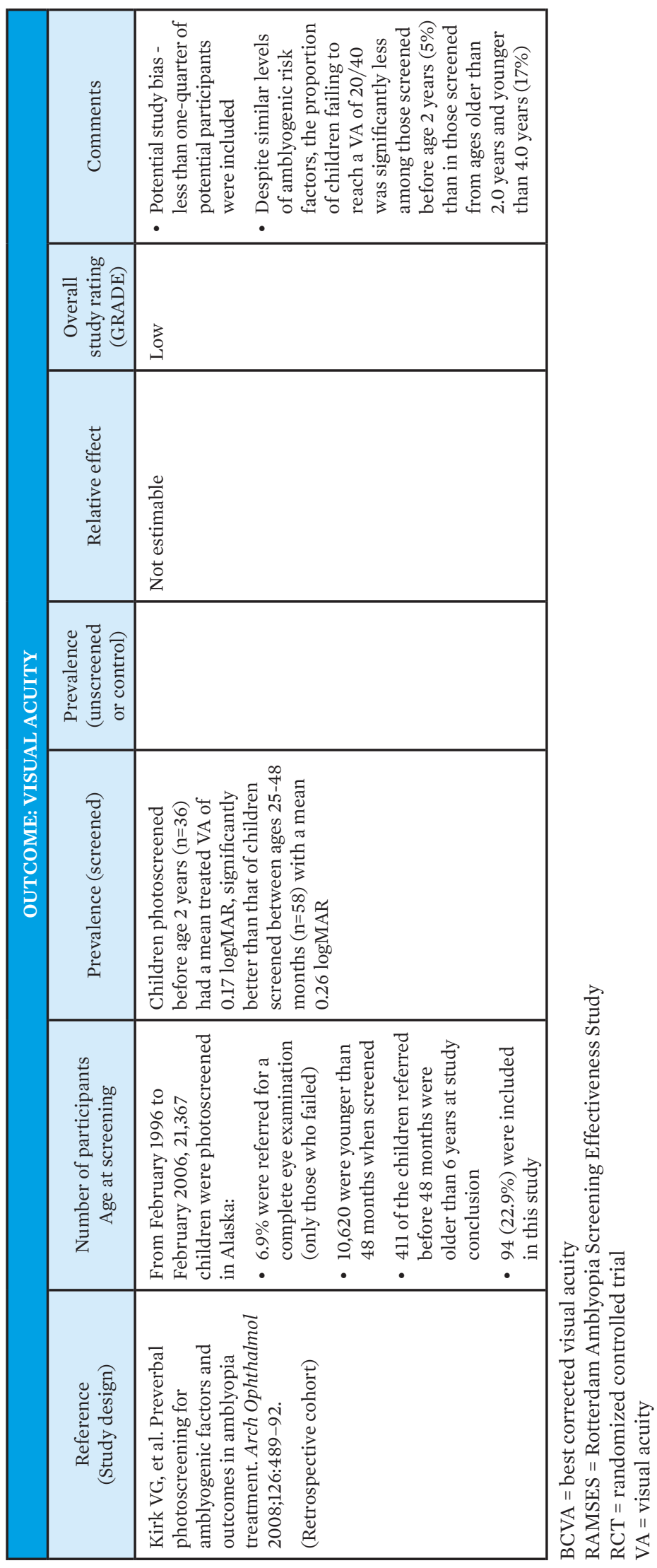


\section{REFERENCES}

1. Robinson BE, Mairs K, Glenny C, Stolee P. An evidence-based guideline for the frequency of optometric eye examinations. Primary Health Care 2012:121; doi 10.4172/2167-1079.1000121.

2. Clinical Practice Guideline Expert Committee. Canadian Ophthalmological Society evidence-based clinical practice guidelines for the periodic eye examination in adults in Canada. Can J Ophthalmol 2007;42:39-45.

3. Amit M; Canadian Paediatric Society, Community Paediatrics Committee. Vision screening in infants, children and youth. Paediatr Child Health 2009;14:246-51. Reaffirmed 01 February 2016, https:// www.cps.ca/en/documents/position/children-vision-screening [accessed 27 August 2019].

4. Dunfield L, Keating T. Preschool vision screening [Technology Report number 73]. Ottawa, ON: Canadian Agency for Drugs and Technologies in Health; 2007.

5. US Preventive Services Task Force; Grossman DC, Curry SJ, Owens DK, Barry MJ, Davidson KW, Doubeni CA, et al. Vision screening in children aged 6 months to 5 years: US Preventive Services Task Force recommendation statement. JAMA 2017;318:836-44.

6. American Academy of Ophthalmology Pediatric Ophthalmology/ Strabismus Panel. Pediatric Eye Evaluations Preferred Practice Pattern ${ }^{\circledR}$ : I. Vision screening in the primary care and community setting; II. Comprehensive ophthalmic examination. San Francisco, CA: American Academy of Ophthalmology; 2012.

7. American Association for Pediatric Ophthalmology and Strabismus. Vision screening recommendations, https://aapos.org//client_data/ files/2014/1076_aapos_visscreen.pdf [accessed 27 August 2019].

8. Rourke Baby Record. Evidence-based infant/child health maintenance guide, www.rourkebabyrecord.ca; 2017 [accessed 27 August 2019].

9. ABCDaire. Recommandations concernant le dépistage des troubles de la vue chez les nourrissons et les enfants.https://enseignement. chusj.org/ENSEIGNEMENT/files/e7/e77f612e-86b5-4e5d-a5d4950459006a81.pdf [accessed 27 August 2019].

10. Jacobson PD. Transforming clinical practice guidelines into legislative mandates: proceed with abundant caution. JAMA 2008;299:208-10.

11. Davis D, Goldman J, Palda VA. Handbook on clinical practice guidelines. Ottawa, ON; Canadian Medical Association; 2007.

12. Canadian Medical Protective Association. Clinical practice guidelines: what is their role in legal proceedings? CMPA Perspective 2011;September:3-5.

13. AGREE Enterprise. Appraisal of guidelines research and evaluation II (AGREE II) instrument, http://www.agreetrust.org [accessed 27 August 2019].

14. Brouwers M, Kho ME, Browman GP, Cluzeau F, Feder G, Fervers B, et al; AGREE Next Steps Consortium. AGREE II: advancing guideline development, reporting and evaluation in healthcare. CMAJ 2010;182:E839-42.

15. Schünemann HJ, Wiercioch W, Etxeandia I, Falavigna M, Santesso N, Mustafa R, et al. Guidelines 2.0: systematic development of a comprehensive checklist for a successful guideline enterprise. CMAJ 2014;186:E123-42.

16. Guyatt G, Oxman AD, Akl EA, Kunz R, Vist G, Brozek J, et al. GRADE guidelines: 1 . Introduction - GRADE evidence profiles and summary of findings tables. J Clin Epidemiol 2011:64:383-94.

17. GRADE Working Group. http://www.gradeworkinggroup.org/; 2017 [accessed 27 August 2019].

18. Guyatt GH, Oxman AD, Vist GE, Kunz R, Falck-Ytter Y, AlonsoCoello P, et al; GRADE Working Group. GRADE: an emerging consensus on rating quality evidence and strength of recommendations. BMJ 2008;336:924-6.

19. Fletcher RH, Fletcher SW, Fletcher GS. Clinical Epidemiology: The Essentials. 5th Edition. Baltimore; Lippincott Williams \& Wilkins:2014:227.

20. Solebo AL, Cumberland PM, Rahi JS. Whole-population vision screening in children aged $4-5$ years to detect amblyopia. Lancet 2015;385:2308-19.

21. Tarczy-Hornoch K, Varma R, Cotter SA, McKean-Cowdin R, Lin JH, Borchert MS, et al; Joint Writing Committee for the MultiEthnic Pediatric Eye Disease Study and the Baltimore Pediatric Eye Disease Study Groups. Risk factors for decreased visual acuity in preschool children: the Multi-Ethnic Pediatric Eye Disease and Baltimore Pediatric Eye Disease Studies. Ophthalmology 2011;118:2262-73.

22. Pai AS, Wang JJ, Samarawickrama C, Burlutsky G, Rose KA, Varma R, et al. Prevalence and risk factors for visual impairment in preschool children in the Sydney Paediatric Eye Disease Study. Ophthalmology 2001;188:495-500.

23. Drover JR, Kean PG, Courage ML, Adams RJ. Prevalence of amblyopia and other vision disorders in young Newfoundland and Labrador children. Can J Ophthalmol 2008;43:89-94.

24. Irving EL, Harris JD, Machan CM, Robinson BE, Hrynchak PK, Leat SJ, et al. Value of routine eye examinations in asymptomatic patients. Optom Vis Sci 2016;93:660-6.

25. Huang J, Maguire MG, Ciner E, Kulp MT, Cyert LA, Quinn GE, et al; Vision in Preschoolers Study Group. Risk factors for astigmatism in the Vision in Preschoolers Study. Optom Vis Sci 2014;91:514-21.

26. Pascual M, Huang J, Maguire MG, Kulp MT, Quinn GE, Ciner E, et al; Vision In Preschoolers Study Group. Risk factors for amblyopia in the Vision In Preschoolers study. Ophthalmology 2014;121:622-9.

27. Varma R, Tarczy-Hornoch K, Jiang X. Visual impairment in preschool children in the United States: demographic and geographic variations from 2015 to 2060. JAMA Ophthalmol 2017;135:610-6.

28. Hendler K, Mehravaran S, Lu X, Brown SI, Mondino BJ, Coleman AL. Refractive errors and amblyopia in the UCLA Preschool Vision Program: first year results. Am J Ophthalmol 2016;172:80-6.

29. Attebo K, Mitchell P, Cumming R, Smith W, Jolly N, Sparkes R. Prevalence and causes of amblyopia in an adult population. Ophthalmology 1998;105:154-9.

30. Friedman DS, Repka MX, Katz J, Giordano L, Ibironke J, Hawse P, et al. Prevalence of amblyopia and strabismus in white and African American children aged 6 through 71 months. The Baltimore Pediatric Eye Disease Study. Ophthalmology 2009;116:2128-34.

31. Pai AS, Rose KA, Leone JF, Sharbini S, Burlutsky G, Varma R, et al. Amblyopia prevalence and risk factors in Australian preschool children. Ophthalmology 2012;119:138-44.

32. McKean-Cowdin R, Varma R, Cotter SA, Tarczy-Hornoch K, Borchert MS, Lin JH, et al; Multi-Ethnic Pediatric Eye Disease Study and the Baltimore Pediatric Eye Disease Study Groups. Risk factors for astigmatism in preschool children: the Multi-Ethnic Pediatric Eye Disease and Baltimore Pediatric Eye Disease studies. Ophthalmology 2011;118:1974-81.

33. Wallace DK, Repka MX, Lee KA, Melia M, Christiansen SP, Morse CL, et al; American Academy of Pediatric Ophthalmology/Strabismus Preferred Practice Pattern Pediatric Ophthalmology Panel. Amblyopia Preferred Practice Pattern ${ }^{\circledast}$. Ophthalmology 2018;125:105-42.

34. González EG, Wong AMF, Niechwiej-Szwedo E, Tarita-Nistor L, Steinbach MJ. Eye position stability in amblyopia and in normal binocular vision. Invest Ophthalmol Vis Sci 2012;53:5386-94.

35. Meier K, Giaschi D. Unilateral amblyopia affects two eyes: fellow eye deficits in amblyopia. Invest Ophthalmol Vis Sci 2017;58:1779-1800.

36. Hubel DH, Wiesel TN. Receptive fields, binocular interaction and functional architecture in the cat's visual cortex. J Physiol 1962;106:106-54.

37. Assaf AA. The sensitive period: transfer of fixation after occlusion for strabismic amblyopia. Br J Ophthalmol 1982;66:64-70.

38. Wiesel TN, Hubel DH. Single-cell responses in striate cortex of kittens deprived of vision in one eye. $J$ Neurophysiol 1963;26:1003-17.

39. Tailor V, Bossi M, Bunce C, Greenwood JA, Dahlmann-Noor A. Binocular versus standard occlusion or blurring treatment for unilateral amblyopia in children aged three to eight years. Cochrane Database Syst Rev 2015;8:CD011347.

40. Sato M, Stryker MP. Distinctive features of adult ocular dominance plasticity. $J$ Neurosci 2008;28:10278-86.

41. Evans BJ, Yu CS, Massa E, Mathews JE. Randomised controlled trial of intermittent photic stimulation for treating amblyopia in older children and adults. Ophthalmic Physiol Opt 2011;31:56-68.

42. Levi DM. Perceptual learning in adults with amblyopia: a reevaluation of critical periods in human vision. Dev Psychobiol 2005;46:222-32.

43. Levi DM, Li RW. Improving the performance of the amblyopic visual system. Philos Trans R Soc Lond B Biol Sci 2009;364:399-407.

44. Eibschitz-Tsimhoni M, Friedman T, Naor J, Eibschitz N, Friedman Z. Early screening for amblyogenic risk factors lowers the prevalence and severity of amblyopia. J AAPOS 2000;4:194-9.

45. Pediatric Eye Disease Investigator Group. A randomized trial of 
atropine vs. patching for treatment of moderate amblyopia in children. Arch Ophthalmol 2002;120:268-78.

46. Barrett BT, Bradley A, Candy TR. The relationship between anisometropia and amblyopia. Prog Retin Eye Res 2013;36:120-58.

47. De Koning HJ, Groenewoud JH, Lantau VK, Tijam AM, Hoogeveen WC, de Faber JT, et al. Effectiveness of screening for amblyopia and other eye disorders in a prospective birth cohort study. $J$ Med Screen 2013;20:66-72.

48. Williams C, Northstone K, Harrad RA, Sparrow JM, Harvey I; ALSPAC Study Team. Amblyopia treatment outcome after preschool screening v school entry screening: observational data for a prospective cohort study. Br J Ophthalmol 2003;87:988-93.

49. Williams C, Northstone K, Harrad RA, Sparrow JM, Harvey I; ALSPAC Study Team. Amblyopia treatment outcomes after screening before or at age 3 years: follow up from randomised trial. BMJ 2002;324:1549.

50. Kirk VG, Clausen MM, Armitage MD, Arnold RW. Preverbal photoscreening for amblyogenic factors and outcomes in amblyopia treatment: early objective screening and visual acuities. Arch Ophthalmol 2008;126:489-92.

51. Groenewoud JH, Tjiam AM, Lantau VK, Hoogeveen WC, de Faber JT, Juttmann RE, et al. Rotterdam Amblyopia Screening Effectiveness Study: detection and causes of amblyopia in a large birth cohort. Invest Ophthalmol Vis Sci 2010;51:3476-84.

52. Vision in Preschoolers Study Group. Does assessing eye alignment along with refractive error or visual acuity increase sensitivity for detection of strabismus in preschool vision screening? Invest Ophthalmol Vis Sci 2007;48:3115-25.

53. Atkinson J, Braddick O, Nardini M, Anker S. Infant hyperopia: detection, distribution, changes and correlates - outcomes from the Cambridge Infant Screening Programs. Optom Vis Sci 2007;84:84-96.

54. Membreno JH, Brown MM, Brown GC, Sharma S, Beauchamp GR. A cost-utility analysis of therapy for amblyopia. Ophthalmology 2002;109:2265-71.

55. Konig HH, Barry JC. Cost-effectiveness of treatment for amblyopia: an analysis based on a probabilistic Markov Model. Br J Ophthalmol May 2004;88:606-12.

56. Holmes JM, Beck RW, Kraker RT, Astle WF, Birch EE, Cole SR, et al; Pediatric Eye Disease Investigator Group. Risk of amblyopia recurrence after cessation of treatment. J AAPOS 2004;8:420-8.

57. Holmes JM, Melia M, Bradfield YS, Cruz OA, Forbes B; Pediatric Eye Disease Investigator Group. Factors associated with recurrence of amblyopia on cessation of patching. Ophthalmology 2007;114:1427-32.

58. Von Noorden GK, Dowling JE. Experimental amblyopia in monkeys. II. Behavioral studies in strabismic amblyopia. Arch Ophthalmol 1970;84:215-20.
59. Baker FH, Grigg P, von Noorden GK. Effects of visual deprivation and strabismus on the response of neurons in the visual cortex of the monkey, including studies of striate and prestriate cortex in the normal animal. Brain Res 1974;66:185-208.

60. Hess RF, Thompson B. Amblyopia and the binocular approach to its therapy. Vision Res 2015;114:4-16.

61. Birch EE, Li SL, Jost RM, Morale SE, De La Cruz A, Stager D Jr, et al. Binocular iPad treatment for amblyopia in preschool children. $J$ AAPOS 2015;19:6-11.

62. American Academy of Pediatrics, Committee on Practice and Ambulatory Medicine, Section on Ophthalmology; American Association of Certified Orthoptists; American Association for Pediatric Ophthalmology and Strabismus; American Academy of Ophthalmology. Eye examination in infants, children and young adults by pediatricians. Pediatrics 2003;111:902-7.

63. Le TD, Raashid RA, Colpa L, Noble J, Ali A, Wong A. Paediatric vision screening in the primary care setting in Ontario. Paediatr Child Health 2018;23:e33-9.

64. Lennerstrand G, Jakobsson P, Kvarnström G. Screening for ocular dysfunction in children: approaching a common program. Acta Ophthalmol Scand Suppl 1995;214:26-38.

65. Schmidt P, Maguire M, Dobson V, Quinn G, Ciner E, Cyert L, et al; Vision in Preschoolers Study Group. Comparison of preschool vision screening tests as administered by licensed eye care professionals in the Vision in Preschoolers Study. Ophthalmology 2004;111:637-50.

66. American Optometric Association. Comprehensive pediatric eye and vision examination: evidence-based clinical practice guideline. 2017:1-67. https://www.aoa.org/optometrists/tools-and-resources/ evidence-based-optometry/evidence-based-clinical-practice-guidlines/evidence-based-clinical-practice-guideline-comprehensivepediatric-eye-and-vision-examination [accessed 27 August 2019].

67. Goldbloom R. Pediatric clinical skills. 4th ed. Philadelphia, PA: Saunders; 2010

68. Sloot F, Sami A, Karaman H, Benjamins J, Loudon SE, Raat H, et al. Effect of omission of population-based eye screening at age 6-9 months in the Netherlands. Acta Ophthalmol 2015;93:318-21.

69. Donahue SP. Relationship between anisometropia, patient age, and the development of amblyopia. Am J Ophthalmol 2006;142:132-40.

70. Zaba JH, Reynolds W, Mozlin R, Costich J, Slavova S, Steele GT. Comparing the effectiveness of vision screenings as part of the school entrance physical examinations in children ages 3 to 6: an exploratory study. Optometry 2007;78:514-22. 